\title{
Um olhar Sartriano para o especialismo "psi" contemporâneo
}

\section{A Sartrean look at the special "psi" contemporary}

\author{
Michelle Thieme de Carvalho Moura* \\ Universidade do Estado do Rio de Janeiro - UERJ, Rio de Janeiro, Rio de Janeiro, \\ Brasil
}

\begin{abstract}
RESUMO
Este artigo busca discutir como as ideias, as quais fundamentam 0 especialismo "psi" de reduções cientificistas, tais como: a busca por verdades generalizantes e a consequente substancialização dos objetos das ciências humanas, acabam sendo hegemônicos nas formas com que lidamos com as contingências da vida na contemporaneidade. Para isso, a autora pretende buscar no pensamento de Jean-Paul Sartre elementos para compreender tal fenômeno, e também para pensar uma proposta de saber psicológico, que fuja da formatação dos sentidos feita pela cultura dos especialismos. Se o homem não pode ser reduzido a uma aparição individual, nem a um mero universalismo, seria um grande equívoco os psicólogos reduzirem a vida e as emoções humanas a explicações generalizantes ou a teorias subjetivistas. Tal dialética universal-singular pode ser vista, portanto, como uma rica ferramenta que Sartre pode nos dar no sentido de repensar a questão do saber psicológico na atualidade.
\end{abstract}

Palavras-chave: Saber psicológico, Especialismo, Jean-Paul Sartre.

\begin{abstract}
This article discusses how the ideas underlying the expertism "psi" of scientistic reductions, such as the search for generalizing truth and subsequent objetivation of the human knowledge, wind up being hegemonic in the ways that we deal with the contingencies of contemporary life. For this, the author intends to search in the thought of Jean-Paul Sartre elements to understand this phenomenon and also to think about a proposal of psychological knowledge that escape from the formatting of meaning developed by the culture of the expertism. If man can't be reduced to a single appearance, nor a mere universalism, it would be a mistake psychologist to reduce life and human emotions into generalized explanations or subjectivist theories. This "universal-unique" dialetic theory would be seen, therefore, as a rich tool which Sartre can give us in order to review the question of psychological knowledge at the present time.
\end{abstract}

Keywords: Psychological knowledge, Expertism, Jean-Paul Sartre. 


\section{Introdução}

Em uma verdadeira revolução educacional, o Centro de Psicologia Positiva da Universidade da Pensilvânia(EUA), sustenta que os princípios para a

busca de uma vida melhor podem e devem ser

ensinados nas escolas. [...] Para o criador da psicologia positiva, citado na reportagem de capa de ÉPOCA na semana passada, nunca houve tanta riqueza material e tão pouca satisfação emocional: "Sou inteiramente a favor do bom desempenho, do sucesso, da disciplina e da alfabetização literária e numérica. Mas imagine se as escolas pudessem, além disso, oferecer a seus alunos os princípios e as limitações para a busca do bem-estar. Teríamos indivíduos e famílias mais felizes, melhores instituições e um mundo melhor", prescreve Seligman. (REVISTA ÉPOCA, 2011)

Eis o que pensei: para que o mais banal dos acontecimentos se torne uma aventura, é preciso e basta que nos ponhamos a narrá-lo. É isso que ilude as pessoas: um homem é sempre um narrador de histórias, vive rodeado por suas histórias e pelas histórias dos outros, vê tudo o que Ihe acontece através delas; e procura viver sua vida como se a narrasse. Mas é preciso escolher: viver ou narrar. (SARTRE, p. 56, 2006)

Os dois trechos acima representam duas formas bem distintas de entender a existência humana, e foram escolhidos como ponto de partida para este trabalho. Na primeira citação temos um trecho de uma reportagem pautada na teoria da Psicologia Positiva, assunto bastante recorrente nas reportagens que envolvem o saber "psi" veiculadas nos meios de comunicação de massa. Na segunda citação, temos um trecho do romance $A$ náusea (2006), no qual Sartre, ao colocar em cena o dilema metafórico do "viver ou narrar", consegue trazer elementos fundamentais para repensarmos 0 saber dos especialistas que, por vezes, acreditam possuir o domínio absoluto das narrativas sobre o homem. Nessa passagem específica Sartre defende a ideia de que, quando narramos uma história, acabamos por nos afastar da existência tal como ela se dá. Assim, narrar uma vida, ou um simples fato, se tornaria algo muito mais confortável do que vivê-lo, porque quando narramos há a atribuição do sentido que queremos, não deixamos margens para as ambiguidades e angústias próprias das contingências da vida. 
Tal fenômeno do narrar, assim como do consequente afastamento da vida concreta, não seria um "sintoma" bem típico dos dias de hoje? São oferecidas uma multiplicidade de produtos no sentido do homem negar sua "náusea", sua condição de abertura, de incerteza. O que a reportagem da primeira citação pretende é justamente oferecer mais uma dessas seduções modernas ao prometer ensinar na sala de aula, a partir de teorias e fórmulas, como ter uma vida feliz. Será isso possível? Existirá uma ciência psicológica que nos ensine então a lidar cotidianamente com dilemas do âmbito da imprecisão e da indefinição? Como definir de forma universal os tais "princípios e as limitações para a busca do bem-estar" que a reportagem fala? Nesse sentido, o discurso da ciência psicológica, que insiste desde os tempos modernos em oferecer sentidos objetivos para a condição nauseante do homem, poderia ser encarado como um desses produtos, os quais "narram" abstratamente as existências humanas ao mesmo tempo em que perdem a particularidade do vivido.

O desenvolvimento de uma Psicologia Experimental, como aponta Husserl (1911/1952), abriu espaço para que os fenômenos psíquicos fossem considerados como substâncias naturais passíveis de mensuração, localizados no tempo e no espaço. A valorização do estudo "científico" da consciência, tanto pela psicologia quanto pela filosofia, faz com que a psicologia científica, neste caso positivista, seja então elevada à ciência básica da filosofia e de todos os outros campos de conhecimento, identificando assim o sujeito do conhecimento ao sujeito psicológico.

Portanto, desde o surgimento da Psicologia científica até os dias de hoje, vemos o fortalecimento contínuo de um determinado tipo de saber "psi", responsável por multiplicar as tentativas de transformar a imprevisibilidade e o estranhamento, caracterizadores do modo de ser humano. Saberes voltados para objetos de pesquisa, dicotomizados do resto do mundo e fechados em si mesmos; através de medicamentos normatizadores, de comercialização de diagnósticos, de mapeamentos cerebrais desenvolvido pelos avanços da neurociência, da literatura de autoajuda etc. Com o passar do tempo mudou-se as nomenclaturas e os meios, mas o homem moderno parece continuar aprimorando sua variedade grande de "antídotos", buscando lidar, de forma mais objetiva, com aquilo que muitas vezes lhe assusta por fugir dos parâmetros técnicos de precisão, nos quais está culturalmente enredado.

Assim, esse trabalho busca discutir como as ideias que fundamentam o especialismo "psi" de reduções cientificistas, tais como: a busca por verdades únicas e objetivas, o culto à previsão e a consequente substancialização dos objetos das ciências humanas, acabam sendo hegemônicos na constituição das formas com que lidamos com as contingências da vida na contemporaneidade. 
Para reafirmar a possibilidade de lidar com o conhecimento psicológico, a partir da abertura de sentidos e não a partir de uma restrição, pretendo buscar na ontologia fenomenológica de Jean-Paul Sartre elementos para repensar uma proposta de saber que inclua a possibilidade da abertura, e que fuja dos ideais cientificistas, os quais tanto justificam e legitimam a necessidade dos especialistas "psi" no mundo contemporâneo.

\section{A constituição da Psicologia enquanto saber científico e possíveis desdobramentos na atualidade}

O poeta e pensador do Romantismo alemão Wolfgang Goethe chamava de o "espírito do tempo" (Zeitgeist) um conjunto de opiniões que dominam um momento específico da história e que, independentemente da percepção humana, atravessam 0 pensamento de todos os que vivem num dado contexto. Villegas Montiel (1996) também aponta para a importância dessa ideia de Zeitgeist, referindo-se a ela como "manifestações compartilhadas quanto ao estilo, forma de vida, ideias e posição espiritual de uma época determinada". (MONTIEL, 1996, p. 94 apud EWALD, 2012). Isto significa dizer, completa Ewald (2012), que há um tecido cultural, uma trama de conceitos que circulam entre nós de várias maneiras e que é compartilhado pela sociedade e época da qual falamos. Tal "tecido cultural" parece ser fundamental para entendermos melhor a constituição da Psicologia, seus saberes e sistemas e sua busca por parâmetros cientificistas que se perpetuam até os dias de hoje. Pensando nisso, talvez seria interessante lembrar como o Zeitgeist dos séculos XVII a XIX pode estar relacionado com a constituição de certas características de um tipo de Psicologia que o grande público demanda e consome nos dias de hoje.

Sartre(1978c), em seu texto "A imaginação", publicado na década de 1930, coloca em cena a discussão sobre o que é a "imagem" e a "imaginação", e ao mesmo tempo mostra como as concepções do século XVII, incluindo aí a concepção cartesiana, permanecem nos princípios da Psicologia até o século $X X$, período em que escreveu o texto. Através do que chama de metafísica ingênua da imagem, Sartre (1978c, p.36) aponta para a tendência dos psicólogos de fazer da imagem uma cópia da coisa, onde a folha de papel "em imagem" é encarada como provida das mesmas qualidades que a folha "em pessoa". Nesse caso, a imagem existiria em si, apareceria e desapareceria a seu critério, e não ao critério da consciência.

No entanto, na concepção sartriana, a imagem não poderia ser encarada como uma coisa que existiria por si mesma. A imagem, para ele, dependeria da relação de sentido que estabelecemos com ela, e essa diferença para Sartre é fundamental. 
Apesar da diversidade de teorias e pontos de vista, Sartre (1978c), aponta que tal ontologia ingênua da imagem, pensada pelos metafísicos dos séculos XVII e XVIII, permanece como fio condutor da constituição de grande parte da Psicologia:

\begin{abstract}
[...] É, no entanto, essa ontologia ingênua da imagem que vamos encontrar, no estado de postulado mais ou menos implícito, em todos os psicólogos que estudaram a questão. Todos ou quase todos fizeram a confusão assinalada mais acima entre identidade de essência e identidade de existência. Todos construíram a teoria da imagem a priori. Sem dúvida, uma leitura superficial dos inumeráveis escritos que foram consagrados, de sessenta anos para cá, ao problema da imagem parece revelar uma extraordinária diversidade de pontos de vista. Desejaríamos mostrar que se pode encontrar, sob essa diversidade, uma teoria única. Essa teoria, que decorre primeiramente da ontologia ingênua, foi aperfeiçoada sob a influência de diversas preocupações estranhas à questão e legada aos psicólogos contemporâneos pelos grandes metafísicos dos séculos XVII e XVIII. Descartes, Leibniz, Hume têm uma mesma concepção da imagem. Só deixam de concordar quando se trata de determinar as relações entre imagem e pensamento. (SARTRE, 1978c, p. 37, grifo nosso)
\end{abstract}

Howard Becker (2009), um conhecido cientista social contemporâneo, aponta para a importância de se entender as consequências do predomínio de determinadas visões de homem e de realidade. Em seu livro Falando da sociedade, ele mostra que todas as formas de representação da realidade emergem em contextos específicos que limitam, por exemplo, o que pode e o que não pode ser pesquisado. Ele atenta então para alguns problemas interessantes que daí decorrem:

Como as necessidades e práticas de organizações moldam nossas descrições e análises (vamos chamá-las de representações) da realidade social? Como as pessoas que usam essas representações chegam a defini-las como adequadas? Essas questões têm uma relação com questões tradicionais sobre saber e contar em ciência. (BECKER, 2009, p. 15-16)

Como não é possível uma determinada visão de homem esgotar o conhecimento sobre a realidade, o autor levanta alguns questionamentos: "Quem faz a seleção das formas aceitáveis de se analisar uma realidade social? Quem considera essa seleção razoável e aceitável? Quem se queixa dela? Que critérios as pessoas aplicam quando fazem esses julgamentos?" (BECKER, 2009, p.32) Através desse raciocínio, a visão de homem passível de ser estudada apenas 
por parâmetros físicos, quantitativos e objetivos, visão essa que pautará o surgimento da Psicologia, passa a não ser mais um fato neutro que guarda uma verdade em si. Como na ciência não há fatos puros sem a existência de teorias pré-existentes (KHUN, 1992), seria um erro acreditar nas existência de uma única verdade que dê conta de toda realidade. Qualquer meio de análise, ressalta Becker (2009), exclui grande parte do fenômeno. "Mesmo os meios que parecem mais abrangentes que as palavras e os números abstratos de que os cientistas sociais costumam lançar mão, deixam praticamente tudo de fora." (BECKER, 2009, p.32)

No entanto, os métodos da física clássica parecem ter sido aceitos como fatos que abarcam toda a realidade, contribuindo fortemente para a ideia de uma Psicologia enunciadora de leis causais e quantitativas. Sartre (1978c), ainda em seu texto $A$ imaginação, ressalta essa ideia apontando que é essa ciência determinista mecanicista que conquista a geração de 1850, época do surgimento das bases da Psicologia. Ele usa a expressão espírito de análise para caracterizar o mecanicismo que tenderia a reduzir um sistema a seus elementos e aceitaria implicitamente o postulado de que estes permanecem rigorosamente idênticos, quer estejam em estado isolado ou em combinação. Assim, Sartre prossegue alertando que para tal espírito de análise, "tomar uma atitude científica em face de um objeto qualquer é postular, antes de qualquer investigação, que esse objeto é uma combinação de invariáveis inertes que mantêm entre si relações externas". (SARTRE, 1978c, p.45). Como consequência, conclui Sartre, todo esforço para constituir uma Psicologia científica implicaria em uma tentativa de converter a complexidade psíquica em um mecanismo:

\footnotetext{
Por esse motivo, a psicologia torna-se uma ciência dos fatos. Pode-se falar com precisão e com pormenores de uma sensação, de uma ideia, de uma lembrança, de uma previsão, assim como de uma vibração, de um movimento físico. [...] Nosso grande problema é saber quais são esses elementos, como nascem, de que maneiras e em que condições se combinam e quais os efeitos constantes das combinações assim formadas. [...] É assim que Taine considera a constituição de uma psicologia científica no prefácio de seu livro l'intelligence, publicado em 1871. (SARTRE, 1978c, p. 46)
}

Dessa forma, um dos principais desafios e problemas da Psicologia em face da sua condição científica seria a tentativa de conciliar a objetividade com a subjetividade. Estaria hoje a dimensão imprevisível caracterizadora da vida humana sendo silenciada e reduzida a parâmetros objetivos de mensuração e controle? Tal preocupação também é recorrente nas reflexões da epistemologia 
crítica de Japiassu, que em sua Introdução à Epistemologia da Psicologia (1975) questiona qual o lugar ocupado pela Psicologia no mundo atual. Japiassu não acredita que a ciência psicológica possa constituir-se excluindo de seu campo de investigação a dimensão não mensurável do homem, a não ser que se construa como uma ciência que nada pode dizer sobre a realidade humana.

Para ele, se a ciência psicológica, para se afirmar, vê-se obrigada a recorrer a um saber científico que se desenrola num domínio onde a verdade só pode falar do lado das coisas, não é de estranhar que, para obter a verdade do sujeito que interroga as coisas, seja necessário, antes, transformá-lo numa coisa que responde. Assim, não teria a Psicologia, em sua busca pela objetividade desmedida, embarcado nessa "grande torrente técnico-científica que sempre mais conquista e domina o mundo e o homem, mas também sempre mais se esquecendo do fenômeno humano?" (JAPIASSU, 1975, p. 139).

De acordo com alguns pensadores, que refletem o cenário atual, entre eles Gilles Lipovetsky (2004) e Nicole Aubert (2004), a atualidade seria melhor caracterizada por um excesso de modernidade, alicerçado em máximas que giram em torno do mercado, da eficiência técnica e do indivíduo. Tal período para esses autores é conhecido como hipermodernidade: Um contexto que estaria favorecendo uma sociedade liberal, fanática pelo desempenho individual, excesso, urgência, hiperfuncionalidade, movimento, fluidez e flexibilidade.

Dessa forma, um paradoxo chama a atenção nesse cenário, visto que ao mesmo tempo que se tem a pretensão de que o homem tudo possa alcançar através de seu esforço individual e recursos internos a serem explorados, cria-se a necessidade dos especialistas e seus procedimentos técnicos. Nas mais variadas esferas sociais ouvimos incessantemente expressões como qualidade total, superação dos limites e dos obstáculos, auto realização, mas o que se tem produzido são sujeitos cada vez mais necessitados de cursos, manuais de autoajuda, métodos, dicas, técnicas contra o estresse, medicações, diagnósticos, etc. Deparamo-nos assim com o paradoxo do sujeito contemporâneo, cuja soberania passa a variar de acordo com o consumo ou não de uma técnica.

Em seu texto A questão da técnica (2002), Heidegger tematiza a importância da abertura de horizontes ao questionar a técnica enquanto 0 modo de desvelamento preponderante na época moderna. Para o filósofo, a técnica, tal como se apresenta para nós, é apenas um dos modos históricos possíveis de desvelamento de sentido e não o único, como muito se propaga na cultura moderna.

Tal desejo por controle traz também o culto à fragmentação. Os especialistas passam então a assumir cada vez mais um olhar fragmentado sobre a vida. Sobre essa busca pela fragmentação na Psicologia contemporânea, Schultz e Schultz (1975) ressaltam que as 
tentativas mais recentes de teorização da psicologia americana são consideravelmente mais circunscritas e restritas, em que o termo "teoria miniatural" ter passado a descrever as teorias de hoje. Algumas dessas teorias tratam de uma única área, como aprendizagem, motivação ou personalidade. Contudo, a maioria delas ocupa-se de funções ou processos ainda mais restritos e tentam explicar uma porção muito pequena do comportamento, reiterando assim o caráter de fragmentação do homem e do saber que fundamenta a noção de especialismo da Psicologia atual.

Assim, a ideia de "Eu" substancializado, que a Psicologia moderna defende para se adequar aos parâmetros da ciência, possibilita a dicotomia eu-mundo e pauta a ideia dos especialistas, os quais acreditam possuir a verdade sobre a consciência.

No meio desse cenário contemporâneo, não é difícil compreender como o saber do especialista "psi", que oferece respostas objetivas e individuais, além de explicações preditivas e universais, passa a ser cada vez mais demandado.

No entanto, considero fundamental entender tal cenário não como uma influência, porque a palavra influência acaba causando uma dicotomia sujeito-objeto. Compartilho, portanto, da ideia de Sartre (1978a), quando aponta que o universal e singular estão intrinsecamente ligados e se afetam mutuamente, de forma indistinta e inseparável. Assim, poderíamos dizer que tal atmosfera da técnica estaria propiciando o surgimento da demanda por este tipo de saber cientificista; e ao mesmo tempo os sujeitos singulares concretos que escolhem tal tipo de saber, estariam ajudando a construir e perpetuar tal cenário, perpetuando assim uma constante tensão dialética, onde não há espaços para dicotomias.

\section{3 o especialismo "psi" de reduções cientificistas e suas manifestações contemporâneas.}

"Será que compete somente à ciência nos explicar e nos dizer o que devemos fazer, o que devemos crer, aquilo que é relevante ou sem importância, o que é bom ou mau, justo ou injusto, verdadeiro ou falso?", nos pergunta Japiassu (1991, p.8). "Claro que não. Mas em todos esses domínios ela intervém.", responde ele mesmo a sua pergunta. Essa intervenção nem sempre aconteceria enquanto saber oficial, mas enquanto instância cultural, espontaneamente reconhecida por todos nós. É justamente tal reconhecimento que possivelmente ajuda a garantir o sucesso desse tipo de saber no modo de vida contemporâneo.

Japiassu (1991) ainda lembra que devido ao prestígio cultural que goza a ciência, não são poucas as ideias que são facilmente acolhidas pelo simples fato de serem produzidas por um "cientista" ou 
"especialista". "Ideias semelhantes, vindas de um filósofo ou de um literato, não teriam o mesmo peso, mas quando são acompanhadas de alguma exposição científica, ganham logo uma dignidade especial." (1991, p. 12)

Tal realidade fica ainda mais evidente quando analisamos a Psicologia que chega à sociedade a partir dos meios de comunicação de massa. Algumas constatações de uma pesquisa realizada por mim, no curso de Mestrado, ajudam a exemplificar perfeitamente esta situação. Nessa pesquisa, realizei uma análise das reportagens que retratam questões "psi", publicadas nos anos 2009 e 2010, nas revistas Época e Veja. A escolha por essas duas revistas se deu por serem as de maior circulação no Rio de Janeiro segundo dados divulgados pelo IVC $^{1}$. Optei por restringir a pesquisa aos anos de 2009 e 2010 porque eles refletem bem o cenário contemporâneo, o qual me proponho a investigar. Como as revistas possuem publicação semanal, observei que o volume de reportagens era grande e a repetição do que aparecia era constante, por isso restringi em dois anos o período das reportagens analisadas. Na revista Época as reportagens referentes a questões "psi" se concentraram nas seções "Saúde \& bem estar", "Sociedade" ou "Ciência e tecnologia". Já na revista Veja as reportagens analisadas estão mais vinculadas à seção de "Saúde" e a de "comportamento". Importante ressaltar que, tanto na Veja quanto na Época, essas sessões são aleatórias, não apresentando assim regularidade nem uma periodicidade fixa.

Durante os dois anos de publicação analisados, tanto a Época quanto a Veja publicaram 101 edições cada. Do total das 202 edições, 86 reportagens se referiam a questões "psi". Dentro dessas 86 reportagens analisadas, 49 apresentaram em seus conteúdos 0 predomínio de uma visão cientificista, pautada principalmente em parâmetros de verdades generalizantes. Já as outras 37 reportagens apresentaram análises mais plurais, porém na maioria das vezes essas reportagens apareceram sem o aprofundamento que as mais cientificistas tinham. Assim, há reportagens que até levam em conta análises mais plurais, envolvendo, por exemplo, a articulação de temas da Psicologia com estudiosos da Filosofia, Sociologia e Antropologia, mas quando se escolhe abordar mais detalhadamente uma perspectiva, parece ser 0 ponto de vista mais cientificista 0 escolhido. A impressão que fica, portanto, é que ciências menos objetivas não são vistas como passíveis de serem aprofundadas nesse tipo de publicação em massa.

Das 49 reportagens com o enfoque mais cientificista, duas tendências chamaram a atenção e foram predominantes: a frequência com que aparecem estudos derivados de pesquisas experimentais (20 reportagens), e também a substancialização da existência advinda dos avanços da neurociência e seus saberes derivados (27 reportagens), sendo que em uma mesma reportagem muitas vezes 
há a combinação de estudos da neurociência e o uso de pesquisas experimentais dos mais variados temas. Outro elemento importante que pode ser observado é o de testes para medir e avaliar algum aspecto emocional (5 reportagens) e a publicação de "guias" ou manuais com orientações dadas por especialistas (10 reportagens).

A tônica comum das pesquisas pautadas em métodos experimentais que aparecem com frequência nas reportagens é o estabelecimento de grupos de controle e tentativas de criação de previsões e relações causais entre variáveis. Mesmo dentro de pesquisas que envolvem temáticas sociais, tais métodos experimentais aparecem com grande força e geralmente são descritos de forma detalhada através de gráficos ou tabelas. O que fica bastante claro nessas reportagens que usam tais métodos experimentais é, portanto, o desprezo pelo singular e pelo concreto, a tentativa de dar respostas generalistas e 0 uso do "discurso competente" (CHAUÍ, 2006) da ciência para legitimar a informação veiculada.

A outra tendência que chama atenção nas análises feitas é o predomínio de reportagens que se utilizam de mapeamentos cerebrais para explicar os estados emocionais e comportamentos. Assim, esquemas detalhados explicando o funcionamento do cérebro nas mais diversas situações da vida também permeiam os conteúdos, indicando uma maciça substancialização da existência, o que reitera e confirma o que já descrevi anteriormente como sendo um grande fenômeno contemporâneo.

Benilton Bezerra e Francisco Ortega (2006) são autores que têm desenvolvido uma série de pesquisas sobre a importância dada ao cérebro em nossa sociedade. Eles mostram que o crescimento das neurociências, a difusão das neuro-imagens por diversas áreas do conhecimento e sua crescente popularização pela mídia têm reforçado cada vez uma nova figura antropológica, que eles chamam de sujeito-cerebral. Para eles, a emergência do sujeito cerebral não é uma consequência necessária do progresso neurocientífico, mas sim a conjugação deste com transformações antropológicas e socioculturais de maior amplitude.

Esses autores chegam à conclusão, portanto, que certas características estruturais da sociedade atual estariam produzindo no imaginário social uma crescente percepção do cérebro como detentor das propriedades e autor das ações que definem o que é o ser humano. Conforme afirmam Ortega e Vidal (2007, p. 258), desde 0 século XIX, o cérebro tem funcionado como um mediador, mas a partir das últimas décadas ele se tornou um verdadeiro ator social. É por isso que tais autores encaram as neurociências como "incrustadas no tecido social, mais do que meramente como tendo 'implicações sociais' ou um 'impacto' na sociedade".

Tais mudanças no tecido social foram decisivas dentro da própria Psicologia. Assim, movimentos como Positivismo, empirismo e 
materialismo converteram-se, com o tempo, nos alicerces filosóficos da Psicologia tida como científica. O sucesso atual de vertentes como o da neuropsicologia, portanto, estaria ainda fortemente pautado na visão de homem do empirismo. O Cérebro e a consciência são cada vez mais empíricos e passíveis de serem analisados, manipulados pela experiência e por estímulos externos. São, portanto, objetos compreendidos com uma materialidade dada no tempo e no espaço, como qualquer outro objeto das ciências exatas.

Um dado interessante apareceu na Revista Veja e ajuda a reiterar ainda mais os questionamentos aqui levantados: De todas as edições analisadas da Revista Veja, uma seção intitulada especificamente "Psicologia" apareceu duas vezes, uma em 2009 e outra em 2010. Uma dessas reportagens (SALVADOR, 2009) pretende explicar o que leva as pessoas a perderem o controle mais facilmente quando estão no meio da multidão, e apesar da sessão ser de Psicologia, o único entrevistado é o Psiquiatra Marcio Bernik, da USP, que explica a situação a partir de fundamentos neurocientíficos: "Quando há percepção de risco iminente, ocorre uma fuga caótica. A atividade cerebral nessa situação ocorre longe do córtex, ou seja, não há pensamento. É uma fuga desorganizada, primitiva." (SALVADOR, 2009, p.156) Já a outra reportagem é baseada em uma entrevista com o psicólogo inglês Jonh Leach, especialista em neurociência, que a partir de experimentos e de análises de ressonância magnética do cérebro, busca entender como as pessoas reagem de formas tão diferentes quando correm risco de vida (PEREIRA, 2009). A maneira como a reportagem aborda o assunto é bastante reducionista, parecendo se utilizar da entrevista com o psicólogo para explicar e reduzir o que acontece com o homem diante de situações de risco de vida a uma série de alterações cerebrais que levam a perda da capacidade cognitiva, colocada como inexorável em cerca de $80 \%$ das pessoas.

É possível dizer que grande parte dos dados retirados das análises feitas aponta mais uma vez para a tendência em se reduzir a complexidade humana a teorias objetivas, universais, imediatas e facilmente assimiláveis, o que nos remete justamente a alguns autores e pensadores do cenário sócio-histórico discutidos já apontados. Assim, acredito ser de fundamental importância pensar tal Psicologia que chega ao grande público através dessas revistas sempre relacionada ao horizonte calculante atual, onde a técnica moderna e seu sentido de funcionalidade, controle, imediatismo e instantaneidade vem impregnando a forma como nos relacionamos com o mundo e encobrindo inúmeras outras possibilidades de desvelamento do homem.

Em seu texto Questão de Método ${ }^{2}$ (1978a), Sartre nos oferece ferramentas para tal compreensão ao apontar para a importância da ciência "situar" os fenômenos que investiga, fazendo com que o 
contexto que envolva o fenômeno seja objeto primordial de análise. Se o homem não pode ser reduzido a uma aparição individual, nem a um mero universalismo, seria um grande equívoco os psicólogos reduzirem as contingências da vida e as emoções humanas a explicações generalizantes.

Dessa forma, a vivência do cenário atual traz com ela uma atmosfera de busca por controle, técnica e fragmentação da vida, que caracterizaria alguns dos determinantes universais que de alguma forma perpassam a forma como cada sujeito concreto se escolhe no mundo. E quando levamos em consideração, por exemplo, a busca observada no cenário atual por um saber "psi" cientificista, que se manifesta não só nas ciências, mas também no modo como cada homem articula seu mundo, fica mais fácil compreendermos como o público que consome e demanda tal tipo de saber acaba ajudando a construir e perpetuar tal cenário.

Assim, os sujeitos singulares concretos que escolhem se restringir a tal busca por referenciais científicos de verdade estão de alguma forma ajudando a escolher também a atmosfera maior em que estão inseridos, mostrando assim a eterna tensão que o movimento progressivo-regressivo implica. Dessa maneira, Sartre desconstrói todas as compreensões psicológicas em evidência até então, colocando em dúvida tanto a perspectiva subjetivista, que acredita em um "mundo interno" portador de uma dinâmica própria, tanto a concepção empírica, que acredita na influência unilateral do contexto sócio-histórico. Por isso Sartre ressalta o tempo inteiro em sua obra a necessidade de trabalharmos com o homem "concreto" e em "situação" impossível de ser abarcado totalmente pela objetividade proposta pelo saber psicológico pautado em verdades únicas, e é isso que pretendo mostrar de forma mais detalhada a seguir.

\section{A fuga do "Nada" e a busca pelo "Ser": Os saberes "psi" em busca de uma objetividade (des)nauseante?}

Pensando em uma possível restrição de sentido proporcionada por tal modo "técnico-científico" de lidar com o homem, filósofos da perspectiva fenomenológico-existencial apropriam-se dos fundamentos da fenomenologia, proposta por Husserl, e passam a tentar olhar para o existir humano de uma forma diferente da habitual. Jean-Paul Sartre é o autor aqui escolhido como base para pensar a possibilidade de um saber psicológico que não pretenda esgotar o homem em um arcabouço teórico técnico objetivante e universalizante.

Sartre problematizou a disciplina psicológica desde seus fundamentos. No entanto, entre os próprios psicólogos, as contribuições de Sartre à Psicologia parecem ser menos conhecidas. 
Em geral estudam nele certas temáticas, entendidas mais como contribuições filosóficas de Sartre à área, como ressalta Schneider (2002). Poucos, porém, valorizam sua relevância na problematização da disciplina psicológica, e este é um dos objetivos deste artigo.

Para tornar mais clara a importância da abertura de sentidos proporcionada pela fenomenologia, Ricardo Jardim (1994) cita um exemplo interessante, que ajuda a mostrar a importância de levarmos em conta a pluralidade de sentidos nos saberes sobre o homem. No exemplo ele pede que imaginemos uma raiz grossa de castanheiro e uma criança pequena que nunca tenha visto nada parecido. A experiência dessa criança com a raiz seduz e horroriza, e cheia de espanto a criança interrogará "O que é isto?". Em seu empenho de introduzir seu filho em nosso mundo impregnado de discursos técnicos e científicos sobre a realidade e a vida, é provável que o pai responda alguma coisa do tipo: "Trata-se de uma bomba aspirante que serve para alimentar a planta e deixá-la presa ao solo." (JARDIM,1994, p.34)

Jardim (1994) aponta que a "bomba aspirante" em sua objetividade e funcionalidade, passa a ser encarada por nós como única possibilidade de aparição daquele fenômeno, fazendo-nos esquecer que para um poeta, um escultor ou um lenhador aquela raiz possivelmente seria vista e analisada de outra forma. Para a fenomenologia, isso que é válido para o exemplo dado da raiz, é válido para toda a realidade, inclusive para a Psicologia. Quando perguntamos ao grande público "O que é a Psicologia?" vemos que a definição cientificista e objetivista não tem sido interpretada como apenas uma visada possível de desvelamento do fenômeno humano, mas sim como a única interpretação legítima, na grande maioria das vezes.

Outra questão fundamental da fenomenologia é o resgate do singular, do vivido, sem ao mesmo tempo abandonar o universal, articulação essa que Sartre também compartilha. Descartes em suas Meditações (1641/1991b) propõe uma espécie de abandono dos afetos e emoções com o intuito de manter a ideia de uma suposta "razão pura" na obtenção do conhecimento. Dessa maneira, podemos dizer que Descartes abandona o singular para defender o universal e 0 mensurável, que se manifesta, por exemplo, em leis gerais do psiquismo que nos ajudam a entender sucessos atuais como os observados na neurociência, nos especialistas do detalhe, nos diagnósticos, por fim, em toda uma ciência que busca na biologia elementos objetivos e práticos para estudar o aparelho psíquico.

Husserl em suas Meditações cartesianas (2001) compreende que o abandono do conhecimento sensível feito por Descartes e o consequente abandono da dimensão irregular e singular, gera um abandono da própria existência. Por outro lado, o abandono do universal possivelmente faria com que caíssemos em um 
subjetivismo. Husserl retoma então o singular através da ideia de consciência como fluxo, como ato, que jamais se materializa. Dessa maneira, articular o singular com o universal é o grande desafio da ideia de intencionalidade que funda a fenomenologia.

Assim, é possível afirmarmos que Sartre se apropria de dois pontos fundamentais da fenomenologia de Husserl: a necessidade de romper com verdades pré-estabelecidas indo "às coisas mesmas", tal como elas se apresentam e se desvelam à consciência, e o consequente rompimento com as dicotomias até então presentes na Psicologia como interior/exterior, potência/ato, aparência/essência, rompimento esse pautado na noção de consciência intencional, como é possível observar no seguinte trecho:

[...] Eis-nos libertados [...]. Libertados da "vida interior" [...] afinal de contas tudo está fora, tudo, até nós mesmos: fora, no mundo, entre os outros. Não é em sabe-se lá qual retraimento que nos descobriremos: é na estrada, na cidade, no meio da multidão, coisas entre as coisas, homem entre os homens (2005b, p. 57).

A ideia que abre a Transcendência do ego, em 1934, de que "Toda consciência é consciência de alguma coisa" é um ponto da obra de Husserl que Sartre se apropria. Sartre, porém, dará a essa ideia um outro alcance, criticando Husserl por esse colocar o eu dentro da consciência, mantendo assim a ideia de interioridade. Para Sartre o sujeito é o próprio visar da coisa(?), o fato de se projetar para ela, acreditando em um eu fora da consciência.

Dessa forma, na introdução do O Ser e o nada (1943/ 2005a), Sartre continua a aprimorar sua crítica a Husserl, e diz que Husserl deu um grande passo colocando a consciência voltada para o objeto com sua proposta de redução fenomenológica.

Porém, posteriormente com a tentativa de uma redução transcendental, Husserl teria caído na ideia que sua própria noção de intencionalidade criticava no início. Para tentar resolver esta questão,Sartre admite que não temos como ter acesso ao ser, apenas ao seu fenômeno. Para Sartre, o Ser não se esgota em um determinado aparecer. É preciso então que haja aquele que aparece (Em-si) e aquele para qual o objeto aparece (Para-si).

O cogito pré-reflexivo seria outra noção que Sartre (2005a) cria, uma espécie de unidade psicofísica que não pode ser confundido com a ideia de "Eu". O cogito é então uma condição, um fundamento que permite tanto a consciência irreflexiva (que tem o mundo exterior como objeto), quanto a reflexiva (que tem a consciência irreflexiva como próprio objeto, fazendo surgir a ideia de "Eu"). Dessa forma, Sartre (1994a) compreende que estabelecemos com o "Eu" a mesma relação que estabelecemos com os outros objetos, sendo esse "Eu" apenas uma possibilidade. Por outro lado será esse "Eu" o recurso 
último da consciência se fechar, pois é ele que traz a ilusão de interioridade e de coerência que o homem tanto busca na tentativa sempre frustrante de completar o vazio constituinte do Para-si.

Referindo-se à ideia de ilusão de interioridade, Lèvy (2001, p.215) diz: "Pode-se, para ter paz, estabelecer uma continuidade entre as subjetivações e chamá-la de caráter ou temperamento. Uma coisa, porém, é fazer como se essa continuidade existisse, outra é acreditar e emprestar-Ihe uma densidade." (LÈVY, 2001, p. 215). Tal noção nos sugere então que, em busca de certezas confortantes, esta busca excessiva e indiscriminada da Psicologia por referenciais atestados como "científicos" poderia também refletir uma desesperadora e frustrante tentativa de fuga da condição de abertura proporcionada pelo para-si. Os critérios científicos de verdade parecem de fato acreditar e emprestar uma densidade a essa continuidade entre as subjetivações e é partindo da crença nessa certeza que o saber psicológico de reduções cientificistas acredita se bastar em si mesmo. Sartre na Transcendência do ego (1994a) ressalta que o "eu" do "eu penso" não é necessariamente aquele que pensa, visto que o "eu" para ele está fora da consciência reflexiva, o "eu", portanto, vira objeto, sendo pura relação. Assim, Sartre critica tanto o Eu material (Moi) formulado pelos psicólogos como polo emanador de desejos, quanto o Eu formal (Je) da filosofia de Kant que Husserl teria resgatado em Ideias relativas a uma fenomenologia pura e uma filosofia fenomenológica (1913). Sartre aponta que Husserl, em sua tentativa de redução transcendental, teria repetido Kant ao sugerir um Eu unificador e individualizante que deveria acompanhar todos os pensamentos. De acordo com Sartre (1994a), esse seria um dos grandes erros de Husserl, o erro de resgatar um eu "transcendental", o eu do "eu penso".

Dessa maneira, Sartre (1994a) defende a ideia de que Husserl, com sua noção de um eu unificador, acaba esquecendo de ir até o fenômeno. Para Sartre, o objeto é transcendente às consciências que o apreendem e é no próprio objeto que se encontra a unidade. Assim, não poderíamos deixar que a realidade dependa apenas do testemunho do sujeito, temos que voltar sempre ao objeto, "às coisas mesmas" que Husserl tanto defendeu inicialmente com sua noção de intencionalidade e epochê. Para isso, Sartre utiliza do método progressivo-regressivo, defendendo ao mesmo tempo a importância da epochê, da singularidade da aparição dos fenômenos, mas ao mesmo tempo levando em conta o contexto histórico-social em que tal fenômeno se dá.

Entretanto, Sartre acreditava que o marxismo dicotomizava o universal do singular ao priorizar os determinantes histórico-políticosociais. Para Sartre, apenas a história humana é dialética, fazendo críticas a perspectiva de Engels - que concebia a existência de uma dialética da Natureza - e a de Marx - que, segundo Sartre, limitava- 
se a verificar o processo dialético na História. Assim, uma importante crítica que Sartre lança contra o marxismo é de ter invertido a relação dialética do homem e sua história porque para ele sem homens vivos, não há história. (QUINTILIANO, 2008). E é por isso que Sartre tanto defendeu, principalmente na fase final de seu pensamento, que

\begin{abstract}
O essencial não é o que foi feito do homem, mas o que ele faz daquilo que fizeram dele. O que foi feito dele são as estruturas, os conjuntos significantes estudados pelas ciências humanas. O que ele faz é a própria história, a superação real dessas estruturas numa práxis totalizadora. (Entrevista de Sartre organizada por PINGAUD, 1968, p. 117)
\end{abstract}

Conforme afirma Quintiliano (2008), a noção de práxis, isto é, o conjunto de atividades no qual cada homem lança-se visando produzir a sua vida, seria, portanto, fator básico capaz de constituir as ações dos grupos humanos. Assim, prossegue ainda a autora, para a constituição da práxis humana, o investigador deve buscar a compreensão dialética na aventura humana, partindo do particular para o geral, do singular para o universal, da vida individual para a História. Por isso, para Sartre, ao partir do indivíduo conseguiríamos chegar ao todo, e vice-versa.

Dentro deste cenário, em que os especialistas são os detentores da verdade, muitas vezes agimos nos fechando no olhar do "outro competente". Este "outro" passa a aprisionar as liberdades que passam a agir como um Em-Si. Sartre (2005a) nos mostra que quando se olha para alguém, este outro é em um primeiro momento uma coisa, um objeto da consciência. Quando o outro aparece agindo no mundo ele desloca o observador e o toma como objeto. Isso causa um conflito que é inerente à própria noção de subjetividade, que é o transitar entre a dialética sujeito-objeto. Um dos possíveis perigos, porém, é quando o sujeito se vê como apenas objeto. Não será isso que de fato acontece quando o homem se restringe e se formata a partir de um saber supostamente tido como verdade incondicional?

Podemos pensar tal questão junto com Chauí (1989), quando ela lembra que para um discurso do conhecimento se tornar "discurso competente" e poder ser mantido, é fundamental que não existam sujeitos humanos portadores de vontades próprias, mas apenas homens reduzidos à condição de objetos passivos. Chauí (1989) então aponta que uma das maneiras mais eficazes de fomentar nos indivíduos que se tomam como objetos a crença de que são sujeitos, consiste em criar uma série de discursos que ensinam a cada um como se relacionar com o mundo, caracterizando assim isso que chamamos hoje de "saberes especializados". 
Sartre (2005a) aponta que essa tendência das doutrinas psicológicas clássicas suprime da consciência qualquer sinal de espontaneidade, autonomia ou responsabilidade, refletindo bem a tentativa de constituir o Para-si como ser plenamente acabado, como um Em-siPara-Si, que se assemelharia muito ao ideal de Deus. Sartre chama isso de "reflexão impura" e aponta que para os psicólogos modernos, todas as manifestações da consciência se integram em uma unidade, a psique, que possui a mesma condição ontológica de um Em-si. Tal psique seria uma espécie de receptáculo que "contém coisas" (imagens, percepções, emoções, etc.), os chamados "objetos psíquicos".

Assim, para Sartre (2005a), essa totalidade que a psique representa, que é o objeto de estudo da Psicologia clássica, até existe, mas existe sob a forma de má-fé, que é uma maneira que a consciência humana tem de lidar com sua condição originária de ser um Nada, com sua inexorável condição de liberdade. Como a consciência por ser Nada existe projetando-se, a busca por uma constância, por uma solidez e, consequentemente, por uma objetividade, seria uma tentativa de fuga da experiência da angústia que vem atrelada à constatação da inexistência de determinações, o que nos ajuda a compreender a enorme demanda por verdades universais e por "saberes especializados", portadores de verdades e relações de causa e efeito nas suas mais variadas formas.

Sartre (2005a), portanto, admite que o homem sendo "Nada" acaba sendo desejo de "ser", desejo de "completude", mas a diferença é que a psicologia clássica nomeia esses "desejos" e oferece soluções prontas para tais desejos, como podemos ver em muitas manifestações do especialismo. A Psicologia clássica se satisfaz em nomear os desejos e os justifica através da suposição de tendências e de essências. Sartre, por sua vez, não dá nome a nada, pois para ele nada pode ser definido originalmente e de maneira puramente abstrata. Uma vez satisfeito um desejo, uma decepção e uma insatisfação se sucedem, visto que a realidade humana está sempre se sacrificando por uma totalidade inatingível.

Ao contrário das concepções da psicologia clássica, a consciência para Sartre (2006b) não é uma coleção de elementos isolados ou desconexos de temperamentos, desejos, emoções, etc., mas deve ser encarada como uma unidade sintética que, embora distinta na soma de suas partes, se reencontra integralmente em cada uma delas. Em seu Esboço para uma teoria das emoções (2006b), Sartre mostra que para o psicólogo, pautado na ideia de interioridade, a emoção é um fato acidental, que "nos acontece", enquanto que para ele, o homem emocionado investiria na emoção todo o seu Ser. A emoção, em última instância, seria a realidade humana que se dirige emocionada para o mundo, é o Para-Si fazendo-se emocionado. 
Exclui-se assim, portanto, a hipótese de que o homem possa ter potências ocultas. Na psicanálise existencial, apesar de Sartre não dar indicações precisas para uma prática psicoterapêutica, é possível pensarmos, inspirados em seu método, que um psicólogo clínico não pode encarar o paciente como um conjunto de categorias diagnósticas, mas sim como uma totalidade inacabada. A realidade de cada homem apresenta-se como sendo, em cada ato, tudo o que manifesta ser, sempre como projeto, como totalização-em-curso por se fazer na ação.

Neste processo de totalização, Sartre (2005a) denomina de circuito de ipseidade a forma como nos relacionamos com o mundo $\mathrm{e}$ estabelecemos sentidos a partir do futuro. Nesse "circuito", o futuro surge o tempo inteiro dando sentido às ações presentes como uma promessa de totalização e unificação. É através da projeção e do "por-vir" que o homem lida com seu passado. E é justamente tal promessa de totalização, por meio do futuro, que oferece ao homem a ilusão de determinação e previsibilidade. O homem é então projeto de ser tal como um Em-si-Para-si, uma consciência completa e determinada.

É possível ver na ânsia contemporânea por explicações biológicas e objetivas e por uma série de outros discursos tidos como "científicos", um exemplo claro da busca por certezas e previsibilidades. Ao se reconhecer em uma categoria diagnóstica, por exemplo, o indivíduo se fecha em algo previamente dado. Agindo como um objeto propriamente dito, o indivíduo tenta então fugir da angústia de ser tomado como uma consciência livre e sem determinações. Uma provocação que Sartre nos permite fazer é, enquanto profissionais "psi", como estaríamos contribuindo para reduzir o homem a essa busca por constâncias, e como consequentemente estaríamos esquecendo de considerar a dimensão de incompletude do para-si que nos diferenciaria dos objetos das ciências exatas.

Assim, Sartre nos ajuda a pensar que o particular em si mesmo não explica tudo, da mesma forma que o universal também não, e a Psicologia que tenta se fechar no saber único sobre o homem parece então não ser suficiente para compreender esse homem. Sartre discute um pouco mais sobre isso quando fala, na apresentação da Revista Le temps modernes(1960), sobre um "atomismo psicológico". Sartre (1960) lembra que ao longo do desenvolvimento das sociedades modernas, e com a consequente divisão do trabalho, produziu-se, por conta do aparecimento e expansão da burguesia, a necessidade de especialistas imbuídos de um "espírito analítico, onde o indivíduo reside como uma ervilha numa lata de ervilhas: redondinho, fechado em si mesmo, incomunicável" (1960, p.17). Tal tipo de espírito analítico teria como princípio o atomismo social, que reduz a sociedade a um mero conjunto de indivíduos, causando assim uma cisão objetiva entre individual e social. 
Tal atomismo social, para Sartre, acarretaria um atomismo psicológico, o qual estaria decompondo experiências humanas em unidades universais, isentas de qualquer dialética com a particularidade do tempo e contexto vivido. Os fenômenos, aponta Sartre (1978a), não podem jamais ser vistos como aparições isoladas. Dessa forma, a ciência deveria estudar a situação em particular sempre inserida em um quadro geral, tendo como função primordial, portanto, fornecer a cada fenômeno, além de uma significação particular, um papel de revelação de algo mais amplo. Tal postura ressalta a importância do método singular-universal que Sartre tanto defendia.

Assim, Sartre acreditava que a psicologia empírica lidava com o homem como se ele fosse algo dado, sem levar em conta, portanto, o sentido e a relação particular da experiência desse homem com o mundo, fazendo, dessa maneira, com que o abstrato se sobreponha ao particular. Tal ideia pode ser observada claramente nesse trecho em conferência publicada no livro Em defesa dos intelectuais (1994b):

\begin{abstract}
A verdadeira pesquisa intelectual, se pretende livrar da verdade dos mitos que a obscurecem, implica uma passagem pela singularidade do pesquisador. Este precisa se situar no universo social para capturar e destruir nele e fora dele os limites que a ideologia impõe ao saber. É no nível da situação que pode agir a dialética da interiorização e da exteriorização; o pensamento do intelectual deve se voltar todo o tempo para si mesmo, para se apoderar sempre como universalidade singular [...] é um trabalho dialético de um universal singular sobre universais singulares, e deve se fazer primeiro no concreto, depois no abstrato. (SARTRE, 1994b, p. 34-35).
\end{abstract}

$\mathrm{Na}$ apresentação do mesmo livro, Francisco Weffort para melhor definir a ideia que Sartre tem sobre o papel do intelectual, dá um exemplo dizendo que um físico que se dedica a construir uma bomba atômica é um cientista, um "especialista do saber prático", enquanto um físico que coloca em questão e discute a construção da bomba é um intelectual. Complementa tal pensamento apontando:

O 'especialista do saber prático' é um ser dividido: é um pesquisador e um servidor da hegemonia. É alguém, portanto, dilacerado entre as exigências da universalidade presentes na prática da pesquisa e os particularismos sociais, econômicos e culturais que condicionam a sua atividade e a sua própria vida. Em outras palavras: é um universalista na técnica e um particularista na submissão à ideologia dominante. Só quando se rebela, o 'especialista' se torna um intelectual. (1994, p. 7) 
Para Sartre (1994b), a classe dominante decide o número dos "especialistas do saber prático" em função do lucro, que é seu fim supremo. Sartre chega a afirmar que, com o advento do capitalismo, a indústria quer se apropriar da universidade para "obrigá-la a abandonar o velho humanismo ultrapassado e substituí-lo por disciplinas especializadas, destinadas a dar às empresas técnicos em testes e estatísticas." (SARTRE, 1994b, p.22). Prossegue discutindo então que os progressos da ciência estavam fazendo diminuir os pensadores e profissionais conhecidos como universalistas, que tentam levar em conta a multiplicidade de saberes e olhares que perpassam seu objeto, e por outro lado ele constatava o aumento de equipes de pesquisadores rigorosamente especializados.

Acreditando que o massacre do pensar tecnocientífico emudece 0 homem na medida em que retira da experiência singular a possibilidade de criação de um sentido próprio para o existir, a proposta de Sartre pode ser vista, portanto, como uma tentativa de abertura para um paradigma que não apreenda a realidade humana levando em conta apenas modelos mecanicistas, mas que também possa permitir reflexões que contemplem a possibilidade de tornar viva a dialética contínua entre existência e mundo, onde um se entrelaça ao outro de forma indistinta e fugidia na grande maioria das vezes.

\section{Considerações finais}

Pretendi mostrar, ao longo deste trabalho, que tendo se passado mais de um século, as questões sobre a verdade, ditada por certos tipos de saberes, não só permanecem na contemporaneidade, mas se aprimoram e se desenvolvem de acordo com o cenário sócio-histórico vigente. Assim, a Psicologia parece possuir hoje uma incontestável pluralidade de vertentes e perspectivas, se pensarmos na sua complexidade epistemológica dentro do campo acadêmico, mas os meios de comunicação de massa que transmitem esse saber ao grande público parecem não refletir essa diversidade.

Através da análise feita de flashes do contemporâneo, que incluem as revistas de grande circulação pesquisadas, tal restrição cientificista no campo "psi" ficou bem demarcada a partir de tendências como a do uso do método experimental e sua consequente tentativa de criação de relações causais, além da busca pela substancialização das mais diversas contingências da vida, usando para isso conhecimentos da neurociência e fenômenos como 0 da matematização da existência.

Pensando na dialética singular-universal proposta por Sartre, o que chama a atenção nessa análise feita da Psicologia que chega ao público através das reportagens é justamente um rompimento dessa 
dialética na medida em que parece haver um predomínio do desprezo pelo singular, e uma busca por universalidades abstratas através do uso constante de esquemas generalizantes. A resposta considerada "verdadeira" sobre os mais variados aspectos da vida humana parece vir associada aos discursos dos especialistas, e o "consumidor" de tais teorias e reportagens é submetido a esse esquema colocado quase sempre como universalmente válido, revelando de certo modo a desconsideração por qualquer sentido singular. O que o Sartre quer mostrar, no entanto, é a importância de não nos perdermos em uma análise puramente singular, mas também por outro lado mostrar 0 perigo que é submeter o homem a regras e classificações puramente abstratas válidas para todos e para qualquer época.

O que pude perceber é que grande parte das discussões feitas acerca do saber "psi", propagado na grande mídia, reflete a tendência em explicar a vida humana a partir de conhecimentos objetivos, universais e facilmente assimiláveis, o que nos remete justamente ao horizonte calculante do mundo atual. Parece ser mais fácil constituir a si próprio através de discursos e saberes já prontos para serem consumidos na lógica da instantaneidade técnica do que tentar criar algo que inclua também a "lógica do sentido", tão bem tecida por Carneiro Leão (1975), lógica essa que demanda um determinado tempo e traz consigo toda uma responsabilização pela escolha tomada. Pensar outras maneiras possíveis de constituir si próprio tem sido, portanto, atitude cada vez mais difícil para o homem inserido nessa sociedade "sob encomenda" que cada vez mais se deixa levar pelos discursos "competentes" na constituição de suas experiências existenciais cotidianas.

Pretendi também mostrar que, para o existencialismo sartriano, a busca excessiva e indiscriminada por especialistas e seus saberes objetivos nos dia de hoje reflete uma desesperadora tentativa de fuga da incompletude que nos constitui, delineando aquilo que Sartre chama de "má-fé". Mentindo para si mesmo, evitando reconhecer-se como um devir, evitando reconhecer a angústia como constituinte de sua liberdade, o homem prefere negar sua condição de abertura e acreditar que aquele estado momentâneo, objetivo e confortável conseguido através de uma verdade vinda de um "especialista", por exemplo, corresponderia aquilo que ele é de fato, ou seja, alguém supostamente livre de frustrações, incertezas e fragilidades.

Assim, levando em conta a existência de tal horizonte técnicocientífico aqui descrito, Sartre tenta dar ao homem a possibilidade de escolher dentro das contingências em que é lançado, oferecendo sempre um espaço para a reflexão e responsabilidade diante de si mesmo. Sobre a inevitável responsabilidade de cada um sobre os modos de estar no mundo hegemônicos, Sartre (1978b, p. 6) já apontava: 
Não há dos nossos atos um sequer que, ao criar o homem que desejamos ser, não crie ao mesmo tempo uma imagem do homem como julgamos que deve ser.(...) Assim sou responsável por mim e por todos, e crio uma certa imagem do homem por mim escolhida; escolhendo-me, escolho o homem.

Esse clássico trecho retirado da conferência Existencialismo é um humanismo já evidencia uma consequência clara do entrelaçamento daquilo que ele chama de singular e universal. Se não há dicotomia entre a ação singular e a ação universal, cada movimento singular ajuda a construir um todo sócio-político-econômico, e esse, por sua vez, em um movimento regressivo, inevitavelmente perpassa o modo como cada singular concreto se escolhe no mundo.

Conforme afirmam Maheirie e Pretto (2007), neste processo de elaboração de seu projeto ou de constituição de sua singularidade em meio à coletividade, o sujeito precisa relacionar-se com o outro, ou seja, ser atravessado pelas condições históricas, e ao fazê-lo, inicia uma relação dialética entre o objetivo e o subjetivo.

Assim, é importante lembrar que uma das preocupações de Sartre quando escreve Questão de Método (1978a) era acusar o marxismo de se tornar cientificista ao colocar uma fatalidade na história de tal modo que o próprio indivíduo não era mais considerado como importante. E a proposta de Sartre era fazer reviver o marxismo por meio da psicologia e psicanálise ao trazer a noção da vivência pessoal de volta, e da antropologia, ao resgatar os pequenos grupos como essenciais para a descoberta do sujeito. Dessa forma, o que Sartre pretendia criticar no marxismo de sua época - a consideração pelo universal e nunca pelo particular e o cientificismo que atingia a análise histórica - aproxima-se muito do que penso ser necessário questionar na psicologia de hoje. $O$ que pretendi mostrar é que esse processo de objetividade e cientificidade atinge até mesmo a psicologia, e para tal questionamento o pensamento de Sartre é uma preciosa fonte de reflexão.

Mas como mostrei ao longo do trabalho, de fato não precisamos viver em permanente luta com a ciência e a técnica para conseguirmos lidar com a singularidade imprevisível de nossas vidas. Não pretendi, portanto, com esse trabalho, exaltar a defesa cega de um conhecimento considerado melhor, visto que eu acabaria caindo no mesmo delírio hodierno de pré-determinar uma verdade como suprema. O que procurei argumentar aqui foi que, diferentemente do massacre tecnicista no qual estamos submersos, as práticas que prezam pela valorização da dimensão humana, demasiadamente humana do objeto da psicologia, devem saber que a unilateralidade de um pensamento é sempre bastante perigosa na medida em que, sem se dar conta, vai sorrateiramente restringindo inúmeras possibilidades de ser. 


\section{Referências}

AUBERT, N. L'Individu hypermoderne. Paris: Éditions Érès, 2004 BECKER, H. S. Falando da sociedade: Ensaios sobre as diferentes maneiras de representar o social. Rio de Janeiro: Zahar, 2009.

BEZERRA, B. Jr.; ORTEGA, F. O Sujeito Cerebral. Viver, Mente \& Cérebro, São Paulo, p. 16-17, julho de 2006.

CHAUÍ, M. $O$ discurso competente e outras falas. In: Cultura e democracia. São Paulo: Cortez Editora, 2006.

DESCARTES, R. Meditações. In: Col. Os pensadores. São Paulo: Nova Cultura, 1991b.

EWALD, A. P. Cabeceios, Cochilos e Esquecimentos: possível articulação entre subjetividade, arte e psicologia social fenomenológica. In: MELO, W.; FERREIRA, A. P. A sabedoria que a gente não sabe. Rio de Janeiro: Espaço Artaud: Programa de Pósgraduação da UFSJ, 2012. No prelo.

HEIDEGGER, M. A Questão da Técnica. In: Ensaios e conferências. Petrópolis: Vozes; Bragança Paulista: Universidade São Francisco, 2002.

HUSSERL, E. A Filosofia como ciência de rigor. Coimbra: Ed. Coimbra, 1952.

. Meditações cartesianas. São Paulo: Madras Editora, 2001.

KUHN, T. S. A estrutura das revoluções científicas. São Paulo: Perspectiva, 1992.

LEÃO, C. E.; LACOMBE, P. F. Existência e psicanálise. Rio de Janeiro: Tempo brasileiro, 1975.

JAPIASSU, H. Introdução à epistemologia da psicologia. Rio de Janeiro: Imago Editora, 1975.

As paixões da ciência. São Paulo: Letras \& Letras, 1991.

JARDIM, R. A. A cultura: O homem como ser no mundo. In: HÜHNE, L. (Org.). Fazer filosofia. Rio de Janeiro: Uapê, 1994.

LIPOVETSKY, G. Os tempos hipermodernos. São Paulo: Editora Barcarolla, 2004.

ORTEGA, F.; VIDAL, F. Mapeamento do sujeito cerebral na cultura contemporânea. Revista Eletrônica de Comunicação, Informação e Inovação em Saúde, Rio de Janeiro, v. 1, n. 2, p. 257-261, jul./dez., 2007.

PEREIRA, C. A ciência do perigo. Revista Veja, Rio de Janeiro, n. 2102, p. 107, 4 Mar. 2009.

SALVADOR, A. O estouro da manada. Revista Veja, Rio de Janeiro, n. 2193, p. 156, 1 dez. 2010.

SARTRE, J. P. Apresentação da revista Les Temps Modernes. In:

Situações II. Lisboa: Publicações Europa-América, 1960.

[entrevista]. In: PINGAUD, B. (Org.). Sartre hoje. São 
Paulo: L'arc documentos, 1968.

. Questão de método. In: . Col. Os pensadores. São

Paulo: Nova Cultura,1978a.

. O existencialismo é um humanismo. In:

Col. Os

pensadores. São Paulo: Nova Cultura:1978b.

- A imaginação. In: . Col. Os pensadores. Nova

Cultura: São Paulo,1978c.

. A Transcendência do ego. Seguido de Consciência de Si e Conhecimento de Si. Lisboa: Edições Colibri, 1994a.

Em Defesa dos intelectuais. São Paulo: Ática, 1994b.

SARTRE, J. P. O Ser e o nada: ensaio de ontologia fenomenológica. 13. ed. Petrópolis: Vozes, 2005a.

Uma ideia fundamental da fenomenologia de Husserl: a intencionalidade. In: Situações I. São Paulo: Cosac Naif 2005b.

A náusea. Rio de Janeiro: Nova Fronteira. 2006a.

L\&PM, 2006b.

Esboço para uma teoria das emoções. Porto alegre:

SCHNEIDER, D. R. Novas perspectivas para a psicologia clínica Um estudo a partir da obra de "Saint Genet: Comédien e martyr" de Jean-Paul Sarte. 2002. 336f. Tese (Doutorado em Psicologia Clínica) Programa de Pós-Graduação em Psicologia Clínica, Pontifícia Universidade Católica de São Paulo, São Paulo.

VILLEGAS MONTIEL, Gil F. Los profetas y el messias: Lukács y Ortega como precursores de Heidegger em el Zeitgeist de la modernidad (1900-1929). México: Fondo de Cultura Económica, 1996.

WEFFORT, F. Apresentação. In: SARTRE, J. P. Em defesa dos intelectuais. São Paulo: Ática, 1994b

\section{Endereço para correspondência}

Michelle Thieme de Carvalho Moura

Rua São Francisco Xavier, 524/10 andar, sala 10.009, bloco F

Maracanã, Rio de Janeiro, CEP 20550-900

Endereço eletrônico: michelle_thieme@yahoo.com.br

Recebido em: $14 / 10 / 2011$

Reformulado em: 21/06/2012

Aceito para publicação em: 30/11/2012

Acompanhamento do processo editorial: Ana Maria Lopez Calvo de Feijoo

\section{Notas}

*Doutoranda em Psicologia Social pela Universidade do Estado do Rio de Janeiro (UERJ), mestre em Psicologia social pela mesma Universidade e especialista em Psicologia Clínica Fenomenológico-Existencial pelo IFEN.

${ }^{1}$ Instituto de verificação de circulação.

${ }^{2}$ Sartre originalmente publicou esse título no plural como Questions de méthode. 
Na versão em português consultada, o tradutor optou por passar o título para o singular. 